See Article page 1765 .

\section{Commentary: In medio stat virtus}

Michele Di Mauro, MD, PhD, MSc, ${ }^{a}$

Massimiliano Foschi, MD, ${ }^{a}$ Gerardo Liberti, MD, ${ }^{a}$ and Antonio M. Calafiore, $\mathrm{MD}^{\mathrm{b}}$

This study from the Bristol Group ${ }^{1}$ in this issue of the Journal focuses strongly on an often-underestimated issue. For example, in the Euroscore II there is no trace of the prognostic role of body mass index (BMI) in relation to 30-day mortality. ${ }^{2}$ Obviously, this is not the first study in this field; Mariscalco and coworkers ${ }^{3}$ have previously highlighted both the presence and the type of correlation linking BMI and hospital mortality in a cohort of 401,227 patients from the National Adult Cardiac Surgery registry, confirming a $\mathrm{U}$-shaped association between mortality and BMI class was observed, but the authors failed to find a relationship between BMI and deep sternal wound problems.

The "obese paradox" was also found in a cohort of 78,762 adult patients in Ontario undergoing first-time coronary artery bypass alone or combined with aortic valve replacement. ${ }^{4}$ A reverse J-shaped relationship exists between BMI range and mortality with their respective hazard ratios, using normal weight as the reference: underweight, 1.35 (95\% CI, 1.23-1.49); overweight, 0.94 (95\% CI, 0.91-0.98); obese, 1.00 (95\% CI, 0.96-1.04); or morbidly obese, 1.12 (95\% CI, 1.06-1.19). Unlike the data reported by Mariscalco and colleagues, ${ }^{3}$ Burns and coworkers ${ }^{2}$ identified a direct relationship between BMI and the occurrence of deep sternal complications: the greater the weight, the higher the deep sternal wound infection.

Why does weight have such a strong influence on postoperative outcome? In the case of obesity, surely cardiac operations, especially mitral valve surgery, are more technically demanding, but the key to a complete answer to this question is inflammation. Obesity prompts a proinflammatory

\footnotetext{
From the ${ }^{\mathrm{a} D e p a r t m e n t}$ of Heart Disease, SS Annunziata Hospital, Chieti and ${ }^{\mathrm{b}}$ Department of Cardiac Surgery, Pope John Paul II Foundation, Campobasso, Italy. Disclosures: Authors have nothing to disclose with regard to commercial support.

Received for publication Nov 12, 2019; accepted for publication Nov 12, 2019; available ahead of print Dec 9, 2019.

Address for reprints: Michele Di Mauro, MD, PhD, MSc Biostat, Heart Disease Department, SS Annunziata Hospital, Via dei Vestini, 66100 Chieti, Italy (E-mail: mdimauro1973@gmail.com).

J Thorac Cardiovasc Surg 2021;161:1774-5

$0022-5223 / \$ 36.00$

Copyright (c) 2019 by The American Association for Thoracic Surgery

https://doi.org/10.1016/j.jtcvs.2019.11.077
}

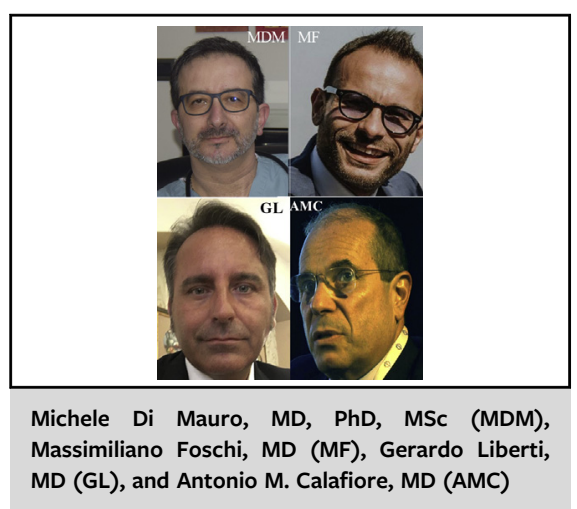

CENTRAL MESSAGE

Obesity and cachexia can be 2 sides of the same coin in patients with mitral valve disease and heart failure, impairing outcomes after surgery.

state via IL- 6 and TNF- $\alpha$ and reduced levels of adiponectin, which plays an anti-inflammatory role. TNF- $\alpha$ is overexpressed in obesity, whereas IL-6 is closely linked to the obese state, which influences the liver to synthesize and secrete C-reactive protein $(>10 \mathrm{mg} / \mathrm{L}$ in very obese patients). A low adiponectin level leads to reduced insulin sensitivity, increasing metabolic abnormalities with higher energy expenditure. In addition, the inflammatory state followed by vascular and endothelial dysfunction is characterized by decreased nitric oxide and elevated reactive oxygen species, leading to oxidative stress. ${ }^{5}$

The patients with mitral valve prolapse could be significantly leaner, especially in the presence of heart failure, and this could be a serious problem when the BMI is $<18 \mathrm{~kg} / \mathrm{m}^{2}$, because these patients at a the greatest risk for death, according to the present study. Obesity and cachexia may be 2 sides of the same coin in patients with valve disease and heart failure undergoing surgery. Cachexia is a complex metabolic wasting syndrome characterized by unintentional edema-free weight loss (muscle mass loss, with or without fat mass loss), inflammation and abnormal biochemistry. ${ }^{6}$ Lower BMI $\left(\mathrm{eg},<18.5 \mathrm{~kg} / \mathrm{m}^{2}\right.$ ) has been associated with higher mortality after left ventricular assist device implantation or cardiac transplantation. ${ }^{7}$

Why is so important to know this link between BMI and outcome after mitral valve surgery? Because, as correctly 
reported by the authors, the findings of this study should lead cardiologist and cardiac surgeon to adopt nutritional management of BMI to achieve risk mitigation, taking into account Aristoteles' words, "in medio stat virtus."

\section{References}

1. Burns DJP, Rapetto F, Angelini GD, Benedetto U, Caputo M, Ciulli F, et al. Body mass index and early outcomes following mitral valve surgery for degenerative disease. J Thorac Cardiovasc Surg. 2021;161:1765-73.e2.

2. Chalmers J, Pullan M, Fabri B, McShane J, Shaw M, Mediratta N, et al. Validation of EuroSCORE II in a modern cohort of patients undergoing cardiac surgery. Eur J Cardiothorac Surg. 2013;43:688-94.
3. Mariscalco G, Wozniak MJ, Dawson AG, Serraino GF, Porter R, Nath M, et al Body mass index and mortality among adults undergoing cardiac surgery: a nationwide study with a systematic review and meta-analysis. Circulation. 2017; 135:850-63.

4. Johnson AP, Parlow JL, Whitehead M, Xu J, Rohland S, Milne B. Body mass index, outcomes, and mortality following cardiac surgery in Ontario, Canada. J Am Heart Assoc. 2015;4:e002140.

5. Ellulu MS, Patimah I, Khaza'ai H, Rahmat A, Abed Y. Obesity and inflammation: the linking mechanism and the complications. Arch Med Sci. 2017;13:851-63.

6. von Haehling S, Ebner N, Dos Santos MR, Springer J, Anker SD. Muscle wasting and cachexia in heart failure: mechanisms and therapies. Nat Rev Cardiol. 2017; 14:323-41.

7. Russo MJ, Hong KN, Davies RR, Chen JM, Mancini DM, Oz MC, et al. The effect of body mass index on survival following heart transplantation: do outcomes support consensus guidelines? Ann Surg. 2010;251:144-52. 